\title{
Breaking the mirror: Asymmetrical disconnection between the phonological input and output codes
}

\author{
Charlotte Jacquemot \\ INSERM U421-IM3, Université Paris XII, Créteil, France, and ENS, Paris, France; \\ Institute of Cognitive Neuroscience, University College London, London, UK \\ Emmanuel Dupoux \\ Laboratoire de Sciences Cognitives et Psycholinguistique, EHESS-ENS-CNRS, Paris, France \\ Anne-Catherine Bachoud-Lévi \\ INSERM U421-IM3, Université Paris XII, Créteil, France, and ENS, Paris, France; \\ Unité de Neuropsychologie, Service de Neurologie, Hôpital Henri Mondor, Créteil, France
}

\begin{abstract}
In this paper, we study the link between the processing systems that sustain speech perception and production in a patient (F.A.) with conduction aphasia. Her pattern of performance in repetition task-quantitative but also qualitative striking difference in errors with pseudowords versus words - cannot be properly accounted for either by a perception deficit or by a production deficit. We discuss this finding according to theoretical models of phonological processing and show that it is best explained by an impaired ability to transfer phonological information from the perception to the production system. We also probed for a phonological link in the opposite direction, from the production to the perception system. F.A.'s results show that this link was not impaired. Overall, our results suggest that (a) the phonological codes in perception and in production are separate but connected by two conversion mechanisms and that (b) these two mechanisms can be disrupted independently.
\end{abstract}

\section{INTRODUCTION}

Speech processing is traditionally conceived of in terms of two separate subsystems, one for speech perception and one for speech production, each of which incorporates several processing levels (phonetic, phonological, lexical, morphological, semantic...). While it is clear that these two subsystems are linked and interact, there is a lot of disagreement regarding how such links are achieved in terms of the processing architecture. From a developmental point of view, language acquisition requires the ability to link speech perception and speech production (Adams \& Gathercole, 2000; Gathercole, 1999; Liberman, Cooper, Shankweiler, \& Studdert-Kennedy,

Correspondence should be addressed to Charlotte Jacquemot, Equipe Avenir/Unité INSERM U421, Université Paris XII, UFR de Médecine, 8, rue du Général Sarrail, 94010 Créteil cedex, Paris, France (Email: charlotte.jacquemot@ens.fr).

We thank Anne Christophe, Odile Decouche, Lisa Feigenson, and Christophe Pallier for their help with this work, and Sophie Scott and Narly Golestani for proof-reading the article. This work was supported by ESRC, by the Fyssen Foundation, by the INSERM through an Interface grant, and by an Avenir grant awarded to A.-C. Bachoud-Lévi. 
1967). In adults' everyday language, a connection between both systems may be useful for monitoring one's own speech output (Levelt, Roelofs, \& Meyer, 1999; Monsell, 1987). In a laboratory setup, tasks like repeating words and pseudowords obviously require connections between perception and production systems. A global architecture of language must account for these abilities.

One can distinguish two opposite theories with many intermediate possibilities. On the one hand, one could propose an organization in which perception and production systems are entirely segregated. In such a framework, the input and output systems only communicate through the most abstract level of representations (the semantic level). On the other hand, one could propose that all levels of representations are shared between perception and production. In such a framework, perception and production can be considered as two modes of functioning of a single interactive system. Between these two extremes, there are a number of options where the processing levels of perception and production systems are connected by automatic and efficient links (see Monsell, 1987). However, these models have not until now being specifically tested. The aim of this paper is to address an unresolved issue concerning the architecture of the language processing at the phonological level: We investigate whether the phonological level is subserved by an unitary code or by two functionally separate input and output codes. Also, if they are separated, we ask what the links might be between the perception and production systems at the phonological level.

The global architecture of language puts heavy constraints on the prediction of error patterns in aphasic patients. Taking the viewpoint that phonological input and output codes are not independent of each other but are drawn from a single phonological network (Liberman et al., 1967; Martin, Dell, Saffran, \& Schwartz, 1994; Martin \& Saffran, 1992, 2002; Patterson \& Lambon Ralph, 1999; Schwartz, Dell, Martin, \& Saffran, Q1 1994; Seidenberg \& McClelland, 1989), impairment of the phonological level should lead to deficit both in perception and in production. On the other hand, if phonological input and output are segregated, they may be functionally dissociated due to brain damage because they draw from separate phonological networks (Howard \& Franklin, 1987; Levelt et al., 1999; Martin, Lesch, \& Bartha, 1999; Monsell, 1987; Nickels, Howard, \& Best, 1997). This hypothesis also supposes that links between input and output can be disrupted independently.

Research on language disorders suggests a certain degree of independence between phonological input and output, because patients with disorders of production can display near-normal comprehension abilities, and, conversely, patients who show a deficit in speech perception can exhibit normal fluency in spontaneous speech (Allport, 1984; Caramazza, Basili, Koller, \& Berndt, 1981; Shallice \& Butterworth, 1977). Evidence from studies with unimpaired subjects is less consensual than are the neuropsychological data. Shallice, McLeod, and Lewis (1985) showed that it is possible for subjects to conduct dual tasks, one involving perception and one production (e.g., detecting an auditory item in a speech stream while reading aloud), suggesting functionally separate processing resources for perception and production. Such a view was further supported by Monsell (1987) who proposed a theoretical model involving separate but linked phonological input and output codes. Nevertheless, in priming studies, cross-modal priming has been reported between perception and production systems, suggesting close connections between these two. These priming studies aimed to identify the time course of semantic and phonological access during word production. They combined auditory or written probes with picture-naming tasks, using probes that held semantic, phonological, or no relationship with the picture names (Peterson \& Savoy, 1998; Schriefers, Meyer, \& Levelt, 1990). The input probes were shown to influence word production at different stages of word processing (semantic and phonological) suggesting that they automatically activate the output system.

Finally, imaging and electrophysiological studies have shown a lot of evidence in favour of very intimately linked if not overlapping brain 
regions for perception and production. Using cortical electrical stimulation techniques, Ojemann (1983) showed that there are cortical sites where electrical stimulation interferes with both the perception and the production of speech, suggesting that these sites play a role in both systems. More recently, a variety of imaging techniques indicated that the left prefrontal regions including Broca's area-which, under the classical theory, are activated during phonological output (Poeppel \& Hickok, 2004) —are also actived during perception (Binder et al., 1997; Price et al., 1996), and that the left superior temporal gyrus, including Wernicke's area-which, under the classical theory, is activated during phonological input (Jacquemot, Pallier, LeBihan, Dehaene, \& Dupoux, 2003; Wise et al., 2001)—also becomes active during production (Buchsbaum, Hickok, \& Humphries, 2001; Heim, Opitz, Muller, \& Friederici., 2003; McGuire, Silbersweig, \& Frith, 1996). Such observations suggest that there is an overlap between the neural systems that participate in phonological processing for both speech perception and production. Furthermore, recent data on "mirror neurons" also suggest a close link between perceptual and motor speech representations. Brain imaging studies (Rizzolatti, Fadiga, Gallese, \& Fogassi, 1996a; Rizzolatti et al., 1996b; Iacoboni et al., 1999; Nishitani \& Hari, 2000) and neurophysiological investigations of the motor cortex (Fadiga, Fogassi, Pavesi, \& Rizzolatti, 1995; Strafella \& Paus, 2000) show that the observation of motor actions also activates the motor circuits involved in the generation of the observed movements. It has been proposed that this observation/execution matching, or "mirror" system, is the physiological expression of a brain mechanism involved in "understanding" the actions made by others: Actions are recognized because both the agent and the observer share the same motor repertoire (Rizzolati et al., 1996a). In the case of speech perception, it has been shown with transcranial magnetic stimulation (TMS) that when subjects listen to verbal stimuli, there is an activation of the speechrelated motor centre and more precisely of the brain area controlling movement of the tongue muscles (Fadiga \& Craighero, 2003; Fadiga, Craighero, Buccino, \& Rizzolatti, 2002). These findings support the motor theory of speech perception. In this theory, speech sounds are perceived by internally reconstructing the intended articulatory movements that could have produced the sounds, assuming that the processes underlying the perception and production of speech sounds share a common abstract motor code (Liberman et al., 1967; Liberman \& Mattingly, 1985).

Overall, evidence both for functionally dissociated phonological input and output codes and for a unitary input/output code has been found. How can we make sense of these contradictory data? Does a common phonological (or motor) code sustain phonological input and output, as the recent imaging studies suggest, or are there separate codes, one for each modality? A possibility for bridging the gap between models suggesting a single phonological code and those suggesting separate phonological input and output codes is to consider the link between perception and production. Specifically, the demonstration of shared brain activation between perception and production tasks is compatible with modular models that propose entirely separate systems for each modality, but which are connected through one or more links. In such models, the presentation of an auditory stimulus may activate the production system through these links, and, vice versa, the programming of speech sounds may also trigger an activation of input code (Indefrey \& Levelt, 2004). In other words, the existence of links predicts shared brain activations during perception and production tasks. Therefore, how can we distinguish between models positing a shared phonological code from those positing separate but linked phonological codes? A way to address this question is provided by studying patients suffering from conduction aphasia. This syndrome is characterized by a severe impairment in speech repetition, combined with relatively intact comprehension as well as fluent speech production marked with some paraphasia and word-finding difficulties (Bartha \& Benke, 2003; Caramazza et al., 1981; Damasio, 1992; Goodglass, 1992). Speech repetition 
involves both perception and production and thus offers the opportunity to assess connections between these two systems.

In this paper, we specifically investigate the link between perception and production at the phonological level, in order to assess whether the phonological input and output codes are functionally independent or not. We report a case study of a patient with conduction aphasia who exhibits a quantitative but also a qualitative striking difference in repetition performance with words versus pseudowords. We discuss these findings and their implications for models of speech perception and production. Our results suggest that phonological input and output codes are functionally separated but connected by links. Further, we explore these links and argue that two independent and opposite conversion mechanisms connect the phonological input and output codes and that these conversion mechanisms can be independently damaged.

\section{CASE REPORT}

Patient F.A. was a 54-year-old, right-handed retired secretary. One year before this study, she had a stroke leading to conduction aphasia. Her comprehension and production were mostly spared but she was impaired in repetition (see Boston Diagnostic Aphasia Examination, BDAE, in Appendix). She also suffered from alexia and acalculia. Digit span performance was within normal limits. Her forward digit span was 4, and her backward digit span was 5. A CT scan (at admission) showed a left middle cerebral artery stroke resulting in a lesion centred on the insular lobe that encompassed the middle part of the left perisylvian area, including middle superior temporal gyrus and sulcus, and the white matter underlying left inferior parietal lobe (see Figure 1).

\section{Speech perception}

\section{Phonological level}

Speech perception was assessed with two tasks. The first task was an AX discrimination task. A trial was composed of two auditory stimuli
(A and $\mathrm{X}$ ) played in succession and separated by $500 \mathrm{~ms}$ of silence. The $\mathrm{X}$ stimulus was either phonologically identical to the A (AA trial), or not (AB trial). A total of 60 pairs of $\mathrm{CV}-\mathrm{CVC}$ (where $\mathrm{C}=$ consonant, $\mathrm{V}=$ vowel) bisyllables were constructed. They were minimal pairs, and they differed in a single distinctive phonetic feature on one phoneme (voicing, place, or manner of articulation). This difference could be on the first, second, or third consonant. Half of the pairs were words, and half were pseudowords. The mean word frequency was low (4.68 per million on the Brulex Database (Content, Mousty, \& Radeau, 1990)). The pseudowords were obtained by exchanging the first syllables of the words in the list. All the pseudowords were hence phonotactically legal and, moreover, contained the same syllables as the words. These pairs were recorded by two speakers (male and female) and were used to construct $120 \mathrm{AX}$ trials. On half of the trials, the two stimuli were produced by a single speaker (male or female) whereas on the other half, the two stimuli were produced by two different speakers. In AA trials in which the stimuli were produced by two speakers, the two stimuli were phonologically similar but acoustically different. The patient was asked to press a button when the stimuli were phonologically similar and another when they were different, irrespective of the speaker's voice.

F.A. performs as well as controls: F.A., 95.8\% correct; controls $(N=9) 96.5 \% \pm 4.03$ correct; $Z$-score $=-0.2, p=.4$. There is no effect of change in speaker (one speaker: $98.3 \%$ correct, two speakers: $93.3 \%$ correct), $\chi^{2}(1)=0.8, p=.3$, lexical status (word: $96.7 \%$ correct, pseudowords: 95\% correct), $\chi^{2}(1)<0.1, p>.1$, or nature of the change (voicing: $100 \%$ correct, place: $96.9 \%$ correct, manner of articulation: $93.8 \%$ correct), $\chi^{2}(2)=1, p=.5$. Therefore, very clearly, the patient has excellent performance, suggesting intact phonological decoding.

\section{Semantic level}

The ability to retrieve semantic information attached to lexical entries should be revealed in a task in which patients have to match a given 

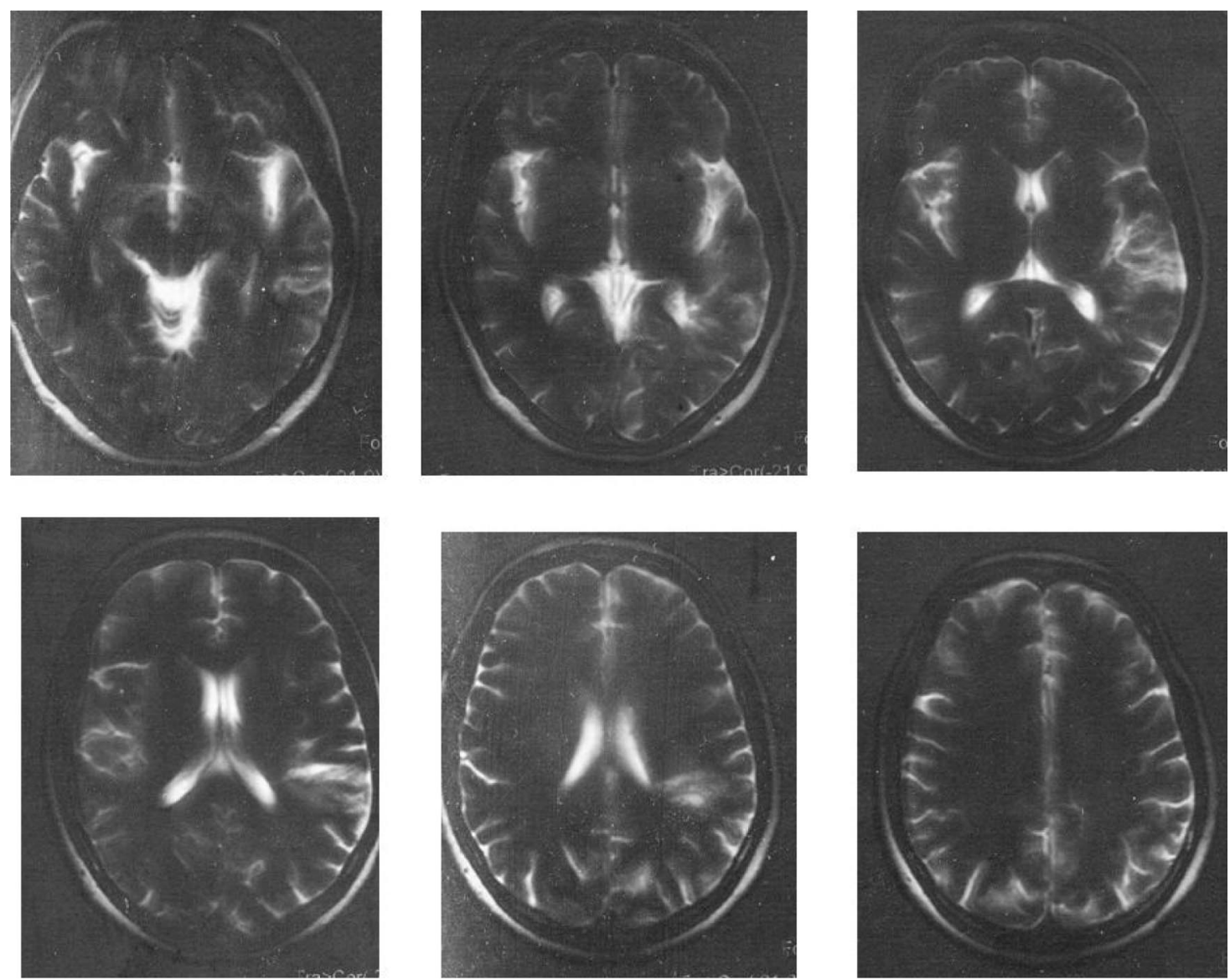

Figure 1. The axial images show damage to the left insular lobe encroaching on the left temporal lobe.

speech input with a picture. Therefore, we administered to F.A. an auditory word-picture matching task. A total of 64 pictures of common concrete nouns were selected and were visually presented immediately following the presentation of an auditory word. The word was the correct name of the picture ( $N=64$; e.g., «bureau» [byRo] desk for a picture of a desk), an unrelated distractor $(N=64$; e.g., "pomme» [pom] apple), a semantic distractor $(N=64$; e.g., "armoire» [aRmwaR] wardrobe), or a phonological distractor. There were two types of phonological distractor: words $(N=64)$ and pseudowords $(N=64)$, which were equidistant from the target word (e.g., the word [bylo] whelk and the pseudoword [byfo]). The patient had to decide whether or not the auditory word corresponded to the picture that followed it.

F.A. performs at a $98.5 \%$ correct level, and there is no effect of distractor type, $F(4,252)=0.4, p=.7$. Her performance does not differ from the one obtained in controls $(N=5 ; 99.8 \% \pm 0.6$ correct; $Z$-score $=-1.6, p=.1)$. Here again, the excellent performance of the patient allows us to exclude problems in word comprehension.

\section{Speech production}

Speech production was assessed with a picturenaming task. A total of 70 pictures were presented, one at a time, and the patient was asked to name them. Picture names were composed of 20 
monosyllabic, 20 bisyllabic, and 20 trisyllabic words (for each of these, half of the words were low frequency, and half were high frequency). There were also 10 quadrisyllabic words of low frequency. For high-frequency and low-frequency groups, frequency was matched across the syllable length: respectively, $F(2,27)=2.2, p=.1$ and $F(3,36)=0.3, p=.8$.

F.A.'s performance is lower than that of controls matched for age and education $(N=5)$ : respectively, $84.3 \%$ and $99.7 \% \pm 0.6$ correct

Q2 responses; Z-score $=-24 ; p<.001$. F.A.'s errors are nonresponses $(N=4)$, phonological $(N=1)$, and semantic $(N=6)$. There is a marginal length effect for the low-frequency words (monosyllabic: $90 \%$ correct, bisyllabic: $100 \%$ correct, trisyllabic: $60 \%$ correct, and quadrisyllabic: $60 \%$ correct), $F(3,36)=2.7, p=.06$, but no length effect for high-frequency words (monosyllabic: 90\% correct, bisyllabic: $90 \%$ correct, and trisyllabic: $100 \%$ correct), $F(2,27)=0.5, p=.6$. When confining the analysis to mono-, bi-, and trisyllabic words (so that the words could be matched for frequency and length), there is no significant frequency effect, $F(1,58)=1.4, p=.2$, nor is there a significant length effect, $F(2,57)=1.2$, $p=.3$. The result of the picture-naming task shows that F.A. is slightly impaired in word production.

\section{FROM PERCEPTION TO PRODUCTION}

\section{Word and pseudoword repetition}

F.A. was tested with a speech repetition task. She was asked to repeat a perceived auditory item. Stimuli were words $(N=96)$ and pseudowords ( $N=48$; see Appendix). Length was controlled in words and pseudowords: one third were monosyllabic, one third were bisyllabic, and one third were trisyllabic. For each length (mono-, bi-, and trisyllabic), words were half high frequency and half low frequency, and frequency was matched across length, $F(2,93)=1, p=.4$; likewise, for each length pseudowords were half high neighbourhood and half low neighbourhood. Low neighbourhood stands for pseudowords that have no neighbour word; a neighbour word is one that can be constructed from a pseudoword by deleting, adding, or substituting a single phoneme.

F.A.'s performance differs from that of the controls (for words, respectively, 82.3\% correct and $99.7 \% \pm 0.5$ correct; $Z$-score $=-37.6$, $p<.001$, and for pseudowords, respectively, $35.4 \%$ correct and $99.6 \% \pm 0.9$ correct; $Z$-score $=-68.9, p<.001)$. The details of the results are reported in Tables 1 and 2 . Interestingly F.A. is dramatically impaired in pseudoword compared to word repetition (words: $82.3 \%$ correct, pseudowords: $35.4 \%$ correct), $\chi^{2}(1)=29.6, p<.001$, whereas this effect is not observed in controls (words: $99.7 \%$ correct, pseudowords: $99.6 \%$ correct). There is a significant interaction between subject group (F.A. vs. controls) and lexical status of the items (words and pseudowords); $Z$-score $=40.7, p<.001$.

F.A.'s errors with words include phonemic errors $(82 \%)$ and semantic errors $(18 \%)$. There is a length effect (monosyllabic words: 96.9\% correct, bisyllabic words: $78.1 \%$ correct, trisyllabic words: $71.9 \%$ correct), $\chi^{2}(2)=7.4, p=.02$, and a frequency effect (high frequency: $87.5 \%$ correct, low frequency: $77.1 \%$ correct), $\chi^{2}(1)=5, p=.03$. F.A.'s errors with pseudowords include phonemic errors (65\%), lexicalization errors (26\%), nonresponses $(3 \%)$, and others $(6 \%)$. There is neither

Table 1. F.A.'s performance in word repetition

\begin{tabular}{lllc}
\hline${\text { No. } \text { syllables }^{\mathrm{a}}}$ & Frequency $^{\mathrm{b}}$ & \multicolumn{2}{c}{ No. correct responses } \\
\hline 1 & High & 16 & $(16 \pm 0)$ \\
& Low & 15 & $(16 \pm 0)$ \\
& Total & 31 & $(32 \pm 0)$ \\
& High & 14 & $(16 \pm 0)$ \\
& Low & 11 & $(16 \pm 0)$ \\
& Total & 25 & $(32 \pm 0)$ \\
& High & 12 & $(16 \pm 0)$ \\
& Low & 11 & $(15.8 \pm 0.4)$ \\
& Total & 23 & $(31.8 \pm 0.4)$ \\
\hline
\end{tabular}

Note: Number of items correct in controls in parentheses. ${ }^{\mathrm{a}} n=32$ in each category. ${ }^{\mathrm{b}} n=16$ in each category. 
Table 2. F.A.'s performance in pseudoword repetition

\begin{tabular}{lccc}
\hline${\text { No. } \text { syllables }^{\mathrm{a}}}$ & Frequency $^{\mathrm{b}}$ & \multicolumn{2}{c}{ No. correct responses $^{2}$} \\
\hline 1 & High & 2 & $(8 \pm 0)$ \\
& Low & 4 & $(8 \pm 0)$ \\
& Total & 6 & $(16 \pm 0)$ \\
& High & 4 & $(8 \pm 0)$ \\
& Low & 4 & $(8 \pm 0)$ \\
3 & Total & 8 & $(16 \pm 0)$ \\
& High & 3 & $(8 \pm 0)$ \\
& Low & 0 & $(7.8 \pm 0.4)$ \\
& Total & 3 & $(15.8 \pm 0.4)$ \\
\hline
\end{tabular}

Note: Number of items correct in controls in parentheses.

${ }^{\mathrm{a}} n=16$ in each category. ${ }^{\mathrm{b}} n=8$ in each category.

a length effect, $\chi^{2}(2)=3.5, p=.2$, nor a neighbourhood effect, $\chi^{2}(1)<0.1, p>$. 1 .

We performed a more fine-grained analysis of error types in the repetition task by classifying them in three categories: deletion, addition, and substitution of phonemes. We calculated for words and pseudowords, the proportion of each error types (see Table 3). The distribution of error types differs significantly between words and pseudowords, $\chi^{2}(2)=6.4, p=.04$, due to a higher proportion of phoneme deletion for words than for pseudowords (respectively, 39\% and 17\%).

\section{Word and pseudoword reading}

F.A. is impaired both in the repetition task (more with pseudowords than with words) and in the picture-naming task. In order to check whether the repetition deficit could be due to a production deficit, we tested her on a reading task using the same items as those used for the repetition task (words and pseudowords). F.A. performs 88.9\% correct in reading, which is significantly different

Table 3. Percentages of error types in the repetition task for words and pseudowords

\begin{tabular}{lcc}
\hline & \multicolumn{2}{c}{ Repetition } \\
\cline { 2 - 3 } & Words & Pseudowords \\
\hline Addition & 0 & 10 \\
Deletion & 39 & 17 \\
Substitution & 61 & 73 \\
\hline
\end{tabular}

from controls' performance $(99 \% \pm 0.5$ correct, $Z$-score $=-28.5, p<.001)$. She makes only phonemic errors. There was no significant difference in performance between word and pseudoword (words: $91.7 \%$ correct, pseudowords: $83.3 \%$ correct), $\chi^{2}(1)=1.4, p=.2$ (see Figure 2). Length and frequency do not influence reading performance with words, respectively, $\chi^{2}(2)=1.9, p=.4$, and $\chi^{2}(1)=0.1, p=.7$, nor did length or neighbourhood influence reading performance with pseudowords, respectively, $\chi^{2}(2)=3.9, p=.1$, and $\chi^{2}(1)=0.1$, $p=.7$.

In comparing F.A.'s repetition and reading performance, we found a significant interaction between task and lexical status of the items (Kruskal-Wallis test, $H=18, p<.001$ ). This interaction was not found in controls (KruskalWallis test, $H<1, p>.1$ ). F.A. is more impaired in repeating than in reading pseudowords (repetition: $35.4 \%$ correct, reading: $83.3 \%$ correct; Wilcoxon test, $z=3.7, p<.001$ ) but similarly impaired in those tasks with words (repetition: 82.3\% correct, reading: $91.7 \%$ correct; Wilcoxon test, $z=1.72, p=.08$ ).

We also compared repetition performance on the present task with that on the picture-naming task described above (Figure 2). Words in the repetition and naming tasks were matched for

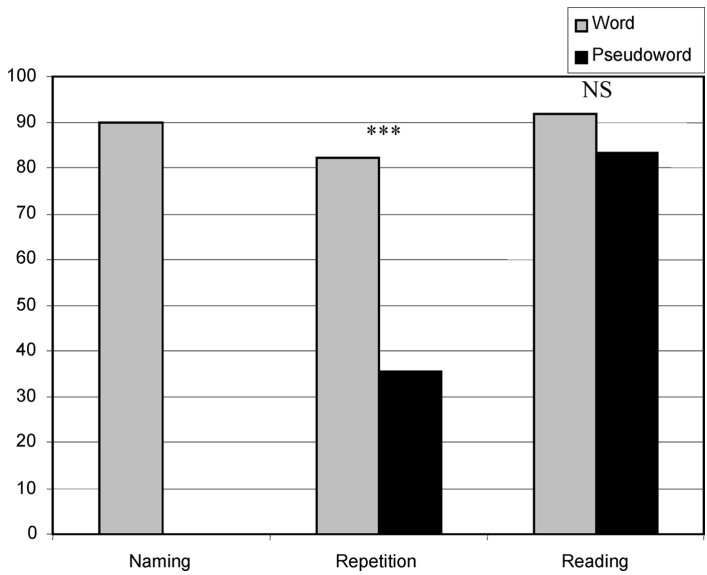

Figure 2. Percentages of the patients' correct responses in naming, repetition, and reading tasks $\left(^{* *}\right.$ for $\mathrm{p}<.001$; ns for nonsignificant).

\section{Q2}


frequency. Performance on word repetition and naming does not differ, $\chi^{2}(1)=0.001, p=.8$, nor does performance on word reading and naming, $\chi^{2}(1)=1.5, p=.21$. Finally, we compared performance considering only monosyllabic, bisyllabic, and trisyllabic words (so that words could be matched for frequency and length). There is no difference between word repetition and naming nor between word reading and naming: respectively, $\chi^{2}(1)=1.96, p=.16$, and $\chi^{2}(1)<0.1, p>.1$.

In sum, F.A. is impaired in her ability to repeat pseudowords relative to words, while her performance during reading aloud does not reveal any significant difference between word and pseudoword production. F.A.'s repetition performance with words is not flawless but comparable to that on other word production tests (reading and naming).

\section{Discussion}

F.A. does not show any speech perception deficit. She performs accurately on speech perception tasks such as the AX discrimination and the auditory word-picture matching tasks, showing that both phonological and lexico-semantic levels are unimpaired in perception. F.A. is slightly impaired in production tasks, roughly to the same extent across several tasks (repetition: $82.3 \%$ correct; reading: 91.7\%; naming: $84.3 \%$ ), suggesting a slight impairment in the speech production. Repetition performance with words is similar to the overall level of performance in the other production tasks, suggesting that errors with words in repetition result from a global word production deficit. In contrast, F.A. is dramatically impaired in pseudoword repetition (35.4\% correct).

The analysis of the pattern of errors in the repetition task shows that performance in repetition differs significantly between pseudowords and words, in terms of the proportion of errors but also in terms of their distribution. These qualitative and quantitative differences fit with an explanation in terms of separate mechanisms involved in word and pseudoword repetition. This supports the view of models involving two pathways between perception and production systems such as the dual route model (e.g., Caplan \& Waters, 1992; Hanley, Dell, Kay, \& Baron, 2004; Hanley, Kay, \& Edwards, 2002). The dual route is composed of a lexico-semantic repetition route that is only available for words and a nonlexical repetition route that can process all stimuli equally well regardless of their lexical status (words and pseudowords; McCarthy \&Warrington, 1984). Typically, patients with impaired speech production perform better at repeating words than at naming them from a picture (Dell, Schwartz, Martin, Saffran, \& Gagnon, 1997). Such a relationship between these two tasks reflects the fact that during word repetition both routes are involved. The lexicosemantic route prevents phonological errors, and the nonlexical route prevents semantic errors by inhibiting words that are phonologically unrelated to the target word (Hanley et al., 2004; Hanley \& Kay, 1997; Hanley et al., 2002; Hillis \& Caramazza, 1991). Nevertheless, such superiority in word repetition over picture naming is not observed in F.A., and pseudoword repetition was dramatically impaired. Knowing that the only available route for repeating pseudowords is the nonlexical, this suggests that this route is impaired. Thus it cannot contribute to word repetition, explaining the absence of more accurate performance in word repetition compared to picture naming. Therefore, the pseudoword repetition deficit does not result from a speech perception nor a production deficit, but rather from a deficit in the link between the perception and production systems at the nonlexical level-that is, at the phonological level.

Let us now examine whether two different models of the nonlexical pathway can accommodate our data. The first model assumes separate input and output pathways and a single phonological code shared by the perception and the production systems (see Figure 3a). In this model, impairment of the nonlexical route could result from damage to the input to the phonological code ( 1 on Figure $3 \mathrm{a}$ ), damage to the output from the phonological code ( 2 on Figure $3 a)$, or damage to the phonological code itself (3 on Figure 3a). In F.A., speech perception was 

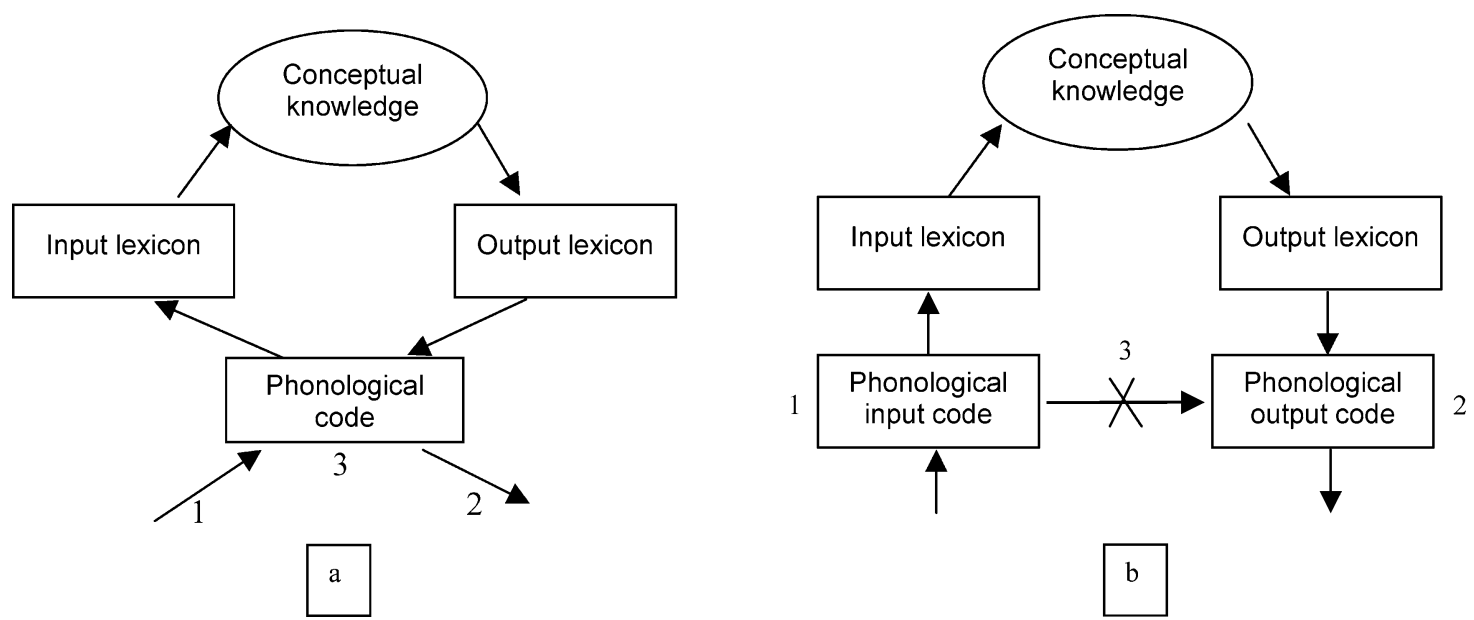

Figure 3. Model of speech processing. In (a) the phonological code is shared by the perception and production systems. In (b) there are two phonological codes, one in the perception system and one in the production system.

flawless. Therefore input to the phonological code and the phonological code itself should be unimpaired (1 and 3 on Figure 3a). Speech production was not perfect. If we suppose that the production errors were due to an impairment to the output from the phonological code ( 2 on Figure $3 a$ ) and that this impairment is also responsible for the errors in repetition, then we would expect to find a quantitative and qualitative comparable pattern of errors during word and pseudoword repetition. It is not the case. Moreover, impairment in the output from the phonological code (2 on Figure 3a) could not explain the significant difference in performance with pseudowords during repetition versus reading. Therefore, F.A.'s repetition deficit for pseudowords must reflect an additional deficit that the model presented in Figure $3 \mathrm{a}$ cannot explain. The second model (Figure 3b) features two phonological codes, one for speech perception and one for speech production, connected by a conversion mechanism. ${ }^{1}$ In this model, a pseudoword repetition deficit could result from damage to the phonological input code ( 1 on Figure $3 \mathrm{~b}$ ), damage to the phonological output code ( 2 on Figure $3 \mathrm{~b}$ ), or damage to the conversion of the phonological input into the phonological output code (3 on Figure $3 b$ ). Given F.A.'s flawless performance on the speech perception tasks, the phonological input code is unimpaired. Again, we can suppose that the production errors are due to an impairment in the phonological output code ( 2 on Figure $3 b$ ). For the same reasons as those described above, this does not explain the worse performance with pseudowords during the repetition task. In this alternative model, this pattern is better accounted for by damage to the link between the phonological input and output codes ( 3 on Figure $3 b$ ). Therefore, to explain our data, we propose a model composed of two phonological codes: one in the perception system (the phonological input code), and the other in the production system (the phonological output code). These two codes are connected by a conversion mechanism that converts one code into the other. This conversion mechanism can itself be damaged.

\footnotetext{
${ }^{1}$ The issue regarding whether the two codes are modality specific (that is, whether the input phonology is built on auditory primitives, and the output phonology on articulatory primitives), or whether they share the same amodal code, remains open. In any event, since these codes are sustained by partly distinct neuronal populations, a mechanism is needed to activate one population when the other is active, and vice versa.
} 


\section{FROM PRODUCTION TO PERCEPTION}

F.A.'s results demonstrate that the conversion mechanism of the phonological input into the phonological output code is impaired. But what about the mechanism in the reverse directionthat is, the mechanism that converts the phonological output into the phonological input code? In other words, is there a unique process linking input and output codes or are there two independent processes that can be selectively damaged? We designed two tasks that require transmission of phonological information derived at output to the input code in order to assess the conversion mechanism of the phonological output into the phonological input code. F.A.'s data were compared to data of five control subjects (mean age 51.6 years, range $50-55$ ).

\section{Rhyme judgement from written words}

The first test was a rhyme judgement task from written words. The patient was asked to decide without speaking whether or not two written words would rhyme if pronounced. This task, in which two strings of letters have to be phonologically compared, requires several steps to be achieved. First, strings of letters have to be converted into a phonological form through the phonological output code (Howard \& Nickels, 2005; Nickels et al., 1997). Then, in order to manipulate the phonological form and to evaluate the rhyme, the phonological forms have to be transferred to the phonological input code as this is the level at which segmentation of the phonological string into onset and rhyme and comparison of two phonological strings occur (Burani, Vallar, \& Bottini, 1991; Howard \& Franklin, 1987, 1990; Nickels et al., 1997; Vallar \& Baddeley, 1984). In covert speech, this transfer involves the phonological link from the output to input codes and could be disrupted by concurrent articulation (Arthur, Hitch, \& Halliday, 1994; Besner, 1987; Brown, 1987; Johnston \& McDermott, 1986). Therefore, accurate performance on this task should reflect the integrity of the phonological link from production to perception.

We constructed two sets of items, rhyming or nonrhyming, each containing 20 pairs of written words. Within the 20 rhyming pairs, there were 10 pairs that were also orthographically similar (e.g., mémoire-armoire, [memwaR]-[aRmwaR], memory-wardrobe) and 10 pairs that were not (e.g., faon-éléphant, [fã]-[elefã], fawn-elephant); similarly, within the 20 nonrhyming pairs, there were 10 dissimilar pairs (e.g., escalier-râteau, [Eskalje]-[Rato], stairs-rake,) and 10 orthographically similar pairs (e.g., fille-tranquille, [fij][tRãkil], girl-peaceful; see Appendix). Thus, the reliance on orthographic or visual information during this task would lead to errors.

F.A. performs lower than controls (respectively, $82.5 \%$ correct and $96.5 \% \pm 2.9$ correct; $Z$-score $=-4.91, p<.001)$. Like controls, she performs better when orthographic information was congruent with the rhyme-that is, during the orthographically similar rhyming condition and the orthographically dissimilar nonrhyming condition: F.A., orthographically congruent pairs: $100 \%$ correct, orthographically incongruent pairs: $65 \%$ correct; $\chi^{2}(1)=6.2, p=.01$; and controls, orthographically congruent pairs: $100 \%$ correct, orthographically incongruent pairs, 93\% correct; Wilcoxon test, $z=2.37, p=.02$.

In this task, subjects first have to silently retrieve the correct phonological form from reading. Because the incongruent pairs were mostly orthographically irregular, and F.A. is slightly impaired in reading, her reading performance may have influenced her rhyme judgement. In order to check this, we compared reading performance and rhyme judgement on the same pairs of words. Overall performance on the reading task does not differ from that for written rhyme judgement (reading task: $82.5 \%$ correct; Wilcoxon test, $z=0, p>.1$ ). Moreover, detailed analyses showed that performance on the rhyme judgement and reading tasks does not differ both for orthographically congruent pairs (respectively, 100\% and 90\%; Wilcoxon test, $z=0.5, p=.6$ ) and for orthographically incongruent pairs (respectively, 65\% and $75 \%$; Wilcoxon test, $z=0.6, p=.5$ ). 
In sum, rhyme judgement performance is similar to reading performance, which makes it likely that the errors in the former may be a result of reading difficulties. F.A. could perform the task on the items that she has no difficulty in reading. Thus, this suggests that the phonological link between output and input is not impaired.

\section{Auditory item-picture matching task}

In order to eliminate the effects of reading impairment and to further assess the phonological link from production to perception, we administered another task that does not involve reading. In this task, F.A. was presented simultaneously with a picture and an auditory item (word or pseudoword), and she had to decide whether the word rhymed with the picture name, or whether it was contained in the picture name (see example below). The patient was told to not produce the picture name aloud. In this test, we used the same pictures as those in the naming task $(N=$ $70)$. For half of the pictures, randomly chosen, the patient was presented with an auditory word and had to decide whether or not it rhymed with the picture name (e.g., a picture of a "sifflet" [sifle] whistle with the auditory word "gonfler" [gõfle] to fill, or the picture of a "girafe" [3iRaf] giraffe with the auditory word "stylo" [stilo] pen). There were 17 "yes" and 18 "no" expected responses. For the other half of the pictures, the patient was presented with an auditory monosyllabic item (24 words and 11 pseudowords) and had to decide whether or not it was contained in the picture name (e.g., the auditory syllable [fo] with a picture of "échafaudage" [e $\left.\int a f o d a 3\right]$ scaffolding). There were 18 "yes" and 17 "no" expected responses. The monosyllabic items not contained in the picture names were randomly extracted from the names of the other pictures. Overall, $50 \%$ of the trials called for a positive response and $50 \%$ for a negative one. In this task, the names of the chosen pictures had a low level of transparency (mean degree of words transparency: $0.73)$. In other words, there was no direct correspondence between orthography and phonology in the picture names: Not all written letters were pronounced, and the same speech sounds could be written in several ways. For instance, the words "sifflet" and "gonfler" rhyme but they are not spelled in the same way, and when asked whether the auditory target [fo] is contained in the picture of an "échafaudage", the syllable [fo] could be written "fo", "feau", "pho", "fau", and so on.

To perform the task, subjects had to manipulate and compare the phonological representation of the picture name with the auditory item. In order to do this, first the picture has to be encoded into a phonological output form. This can be done in two ways: (a) producing the picture name internally and thereby accessing its phonological output form or (b) retrieving the orthographic representation of the picture and then converting it into a phonological output form. At the same time, the subjects perceived the auditory item and encoded it at the phonological input level. They then had to compare the two phonological forms (from the picture and from the auditory item). This involves the transfer of the phonological output to the phonological input where the phonological analysis can be performed.

F.A.'s performance is lower than that of controls (respectively, 90\% and 99.7\% \pm 0.64 correct; $Z$-score $=-15.2 ; p<.001)$. Both in F.A. and in controls, there is no significant difference between the rhyme detection and syllable detection conditions: F.A., respectively, $82.9 \%$ correct and 97.1\% correct; $\chi^{2}(1)=2.5, p=.1$; and controls, respectively, $99 \%$ correct and $100 \%$ correct; $F(1$, $68)=1, p=.3$. In the syllable detection condition, there was no effect of the lexical status of the auditory item (word: $95.2 \%$ correct and pseudoword: $100 \%$ correct); $\chi^{2}(1)<0.1, p>.1$. We also compared F.A.'s performance with picture-naming performance on the same set of pictures: Performance on the rhyme detection task and on the syllable detection task does not differ from that on the naming task (respectively, Wilcoxon test, $z=1.6, p=.1$, and Wilcoxon test, $z=0.24, p=.8$ ).

\section{Discussion}

We constructed two tasks in order to assess the conversion of the phonological output into the 
phonological input code. The first task required the patient to covertly access the phonological representation of two written words, to segment them into onset and rhyme and to compare the two rhymes. F.A.'s performance is good although not perfect, but similar to that obtained during the reading task with the same stimuli. Therefore the errors observed during the written rhyme judgement task can be attributed to reading errors rather to an impairment of the mechanism that converts the output code into the input code. The second task required the covert retrieval of a picture name, the segmentation and the manipulation of its corresponding phonological form, and comparison with the phonological representation of an auditory item (pseudoword or word). Again, F.A.'s performance is good, although lower than the controls, and does not differ from performance on the naming task using the same pictures. It is possible, then, that the principal source of F.A.'s errors in this task could be due to her impairment in generating the correct phonology of the picture name. This means that the patient could perform the crucial aspect of these tasks, which was to transfer the phonological output into the phonological input code.

We have of course, to address the alternative hypotheses that these two tasks could be done using the phonological output code only. First, regarding rhyme judgements from written words, many studies have assumed that such tasks that require the inner production of a phonological output, its segmentation into phonological units, and the comparison of these phonological units can only be performed at the phonological input code (Howard \& Franklin, 1987; Howard \& Nickels, 2005; Nickels et al., 1997). A possible justification for this assumption might be that since perceptual system is naturally equipped for segmentation and comparison of phonological forms, it would be redundant and not economical to duplicate these processes in production system. Such an economy argument has been made by Levelt $(1983,1989)$ and Wheeldon and Levelt (1995) who proposed that access to the various stages of the production system is performed through an internal loop to the speech comprehension system. We recognize that economy arguments are not totally satisfactory and that rhyme judgement from written words could be done at the phonological output code in a model in which the phonological output can be inspected, segmented, and monitored. Second, in the case of the auditory item-picture matching task, the auditory item could not have been transferred from the phonological input to the phonological output code because of F.A.'s impairment in the link from phonological input to output code.

A second possibility that we have to address is that these tasks are performed at a lexical level rather than at a phonological level. In order to ensure that the patient was not using a lexical output to input mapping instead of a phonological output to input mapping, we used words and pseudowords as auditory targets in the second task. Even if auditory words can access the lexical level, pseudowords can only be encoded at the phonological level. Therefore, if the patient used a lexical strategy to perform the task, we would have observed lower performance on trials involving auditory pseudowords. In contrast, F.A. succeeded equally in performing the task regardless of the lexical status of the auditory target. This allows us to assume that the patient used a phonological output to input mapping in order to perform this task.

Finally, one may argue that the task could have been performed by using an orthographic rather than a phonological code: for instance, in the auditory item-picture matching task, by retrieving the orthographic representation of the picture name and comparing it with the result of a phonemegrapheme transcoding of the auditory item. However, using an orthographic strategy might not have been useful given that there were nontransparent picture names. Moreover, there were many orthographic ways of representing the same auditory item, preventing the patient from using an orthographic strategy. In addition, this strategy would involve the manipulation and the comparison of orthographic forms-processing supposed to be slightly impaired in F.A. given her deficit in reading. We could therefore 
reasonably discard the possibility that F.A. used an orthographic strategy to directly map the orthographic codes of the picture names and the auditory items.

In sum, the rhyme judgements task from written words and auditory item-picture matching task were designed to assess the phonological link between output and input codes. The mentioned alternative strategies could be reasonably ruled out, and this confirms that these two tasks require the transfer of phonological form from output to input code. F.A. is not as accurate as the controls are on both tasks. Nevertheless, her performance does not differ from her reading performance for the former task and from picturenaming performance for the latter. We could assume, then, that F.A.'s errors in these two tasks originate from impairment in generating the correct phonological output form from written words and pictures. This suggests that the conversion mechanism of the phonological output code into the phonological input code is not impaired.

\section{GENERAL DISCUSSION}

In the first part of the paper, we investigated whether phonological input and output are subserved by a common code or by two functionally separate codes connected by a link. The detailed study of F.A., a conduction aphasic patient, shows that her repetition deficit affects pseudowords dramatically more than words, and it suggests a deficit in the link between phonological input to output codes, the only pathway available for the repetition of pseudowords. Other studies have reported cases of patient with impaired performance in repetition (Bartha \& Benke, 2003; Caramazza, Miceli, \& Villa, 1986; Damasio, 1992; Goodglass, 1992; Howard \& Nickels, 2005; Saito, Yoshimura, Itakura, \& Lambon Ralph, 2003; Shallice, Rumiati, \& Zadini, 2000). But repetition deficits were usually coupled with phonological deficits in perception or in production, and it therefore remained unclear whether these repetition deficits depended on perception or production deficits or whether they were due to a specific deficit in the link between the perception and production systems (Caplan, 1992; Damasio, 1992; Kohn \& Smith, 1990; Vigliocco, Antonini, \& Garret, 1999; Wilshire \& McCarthy, 1996). In addition, contrary to F.A., when tested the patients did not exhibit any qualitative difference in repetition errors between words and pseudowords (Caramazza et al., 1986; Shallice et al., 2000). These last studies reported cases of patients that were more impaired on pseudoword repetition than on word repetition, but this difference between word and pseudoword performance was also observed in reading tasks (see Shallice et al., 2000, for a review). Consequently, they interpreted their finding in terms of an impairment of the phonological output buffer. In contrast, in the current study F.A. is more impaired on pseudoword repetition than on word repetition, while her performance on the reading task does not differ for words and pseudowords, making an explanation of an output buffer deficit unlikely. Similarly F.A.'s deficit could not be explained by an impairment of the input system because her performance on speech perception tasks (on both words and pseudowords) was flawless. These observations allowed us to discard the hypothesis that the repetition deficit stemmed from a phonological impairment in the perception or in the production systems. The only explanation that can account for the observed deficit in pseudoword repetition is that of an impaired conversion process of the phonological input into the phonological output code. This result implies that the phonological code is not common to the perception and production systems, but is instead instantiated in a modality-specific way in the input and output systems and is connected by conversion mechanisms. This result is consistent with the hypothesis of separate phonological input and phonological output codes (Howard \& Franklin, 1987; Howard \& Nickels, 2005; Monsell, 1987) and confirms previous behavioural data that suggest that speech perception and production processes are functionally separate (Caramazza et al., 1981; Shallice \& Butterworth, 1977; Shallice et al., 1985). 
In the second part of the paper, we asked whether the conversion of phonological input into phonological output could be disrupted independently from the conversion in the opposite direction-that is, from phonological output into phonological input. If there are two functionally and anatomically segregated conversion processes, then the disruption of one of them might have no effect on the other (Monsell, 1987; Nickels et al., 1997). F.A.'s performance in rhyme judgement as well as in auditory item-picture matching tasks shows that the conversion mechanism of the phonological output into phonological input code is not impaired, suggesting that it may be selectively spared. Indeed, we propose a model including the perception and production systems, which is composed of two phonological codes (input and output) connected by two opposite conversion processes (see Figure 4). Previous studies on aphasic patients with repetition deficits also reported deficits on rhyme judgement tasks with written words (Feinberg, Rothi, \& Heilman, 1986; Howard \& Franklin, 1987, 1990; Waters, Rochon, \& Caplan, 1992). To our knowledge, however, our patient is the first reported case showing a specific impairment of the mechanism

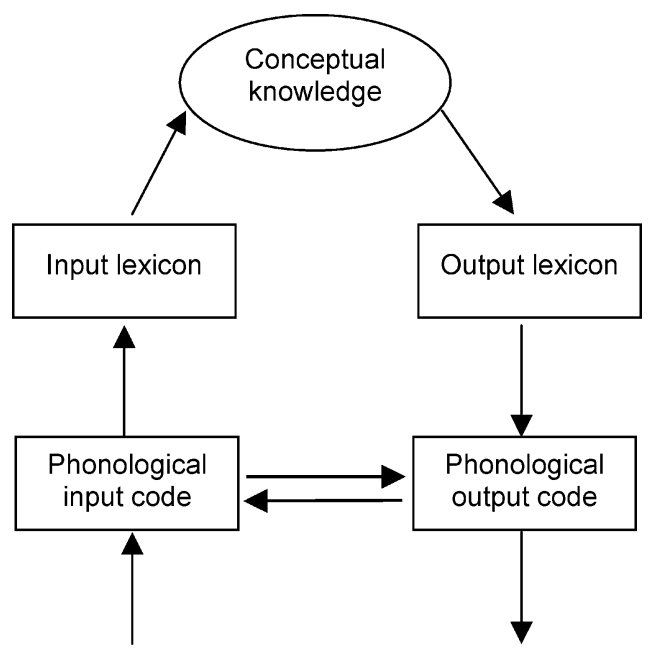

Figure 4. Model of speech processing composed of two phonological codes, one in perception and one in production. These two phonological codes are connected by two separate links. that converts the phonological input into the phonological output code in the absence of a reverse impairment.

How do we reconcile these results with functional magnetic resonance imaging (fMRI) or TMS studies showing anatomical overlap for phonological input and phonological output codes? While it is clear that the dissociation of brain regions for two tasks can be interpreted in terms of separate processes, it is more difficult to interpret the presence of common areas for two tasks as reflecting common processes. On the one hand, the overlap observed in imaging studies could be the result of activation of two anatomically close or overlapping regions that do not share any functional components. On the other hand, the common pattern of activation for perception and production could reflect activation of input and/or output networks that functionally activate each other. For example, research on speech perception has emphasized the role of inner rehearsal in native language acquisition (Baddeley, Gathercole, \& Papagno, 1998) as well as in foreign language acquisition (Gathercole, 1999; Gathercole, Service, Hitch, Adams, \& Martin, 1999; Masoura \& Gathercole, 2005). Moreover, it has been shown that subjects are faster in pronouncing a syllable $(/ \mathrm{pa} /, / \mathrm{ta} /$, or / $\mathrm{ka} /)$ in response to hearing that same syllable than in response to hearing another one, suggesting that subjects may engage inner rehearsal during speech perception (Fowler, Brown, Sabadini, \& Weihing, 2003). It seems, therefore, that the representation of spoken word could activate the phonological output code through covert rehearsal. Vice versa, Wheeldon and Levelt (1995) have proposed that speech production involves several monitoring loops. The ability to self-monitor is a necessary component of any speech production system. There is much evidence to suggest that speakers are able to detect and edit out errors in external speech, be it the speech of another person or that of oneself (see Levelt, 1989, for a review). In addition, studies have been conducted that demonstrate that errors can be detected and repaired prior to articulation in both spontaneous speech (Levelt, 
1983) and experimentally induced speech (Motley, Camden, \& Baars, 1982). This monitoring loop recycles motor plans onto the speech perception system and is responsible for the spontaneous correction of speech errors before such errors are produced. Wheeldon and Levelt (1995) provided evidence that the code underlying internally generated speech is a syllabified, phonological representation, and they suggested that the internal monitoring loop works by using the phonological output representation as input for the perceptual network. Therefore, the mechanism that converts the phonological output code into an input code is a good candidate for this inner transmission of information between the two systems and for internal monitoring (Indefrey \& Levelt, 2004; Levelt et al., 1999). Such conversion mechanism is also activated by any task requiring the generation of a phonological code, as it does not require the generation of articulatory gestures per se and supports our ability to internally "hear" a word or a pseudoword without generating articulatory commands and pronouncing the word as proposed by McGuire et al. (1996; see also Blank, Scott, Murphy, Warburton, \& Wise, 2002; Price et al., 1996). Therefore, rehearsal and monitoring may cause common activation patterns during perception and production tasks even if the perception and production systems involve separate networks.

At the anatomical level, a recent functional connectivity study revealed a bidirectional connection between Broca's and Wernicke's areas probably through the arcuate fasciculus (Matsumoto et al., 2004). The authors' view differs from the classical Wernicke-Geschwind model, which assumes connections from Wernicke's area to Broca's area but not in the reverse direction Q3 (Geschwind, 1970). Thus, the arcuate fasciculus may not be a unidirectional pathway but rather a bidirectional system that conveys information between the two language areas. This finding provides anatomical support for our model. Unfortunately, the arcuate fasciculus is not visible on the anatomical brain images of F.A.'s lesion, and we therefore cannot confirm the predicted lesion in this pathway. Further research will allow the testing of predictions regarding bidirectional connections within the arcuate fasciculus: The two pathways should at least be partly anatomically segregated because our results suggest that they could be independently damaged.

In conclusion, the results of this case study show that the source of the pseudoword repetition deficit in our conduction aphasic patient is an impairment in the conversion mechanism of the phonological input into the phonological output code. These results suggest that the phonological code is not common for the perception and production systems, but instead that there are two separate but connected phonological codes, one in perception and one in production. Our results also suggest that there are two conversion mechanisms between the two phonological codes, one from perception to production and one from production to perception, and that these can be selectively damaged.

Manuscript received 28 May 2004 Revised manuscript received 30 September 2005 Revised manuscript accepted 7 March 2006 PrEview proof published online day month year

\section{REFERENCES}

Adams, A. M., \& Gathercole, S. E. (2000). Limitations in working memory: Implications for language development. International Journal of Language and Communication Disorders, 35, 95-116.

Allport, A. (1984). Speech production and comprehension: One lexicon or two? In W. Prinz \& A. F. Sanders (Eds.), Cognitive and motor processes. Berlin: Springer-Verlag.

Arthur, T. A. A., Hitch, G. J., \& Halliday, M. S. (1994). Articulatory loop and children's reading. British Journal of Psychology, 85, 283-300.

Baddeley, A., Gathercole, S. E., \& Papagno, C. (1998). The phonological loop as a language learning device. Psychological Review, 105, 158-173.

Bartha, L., \& Benke, T. (2003). Acute conduction aphasia: An analysis of 20 cases. Brain and Language, 85, 93-108.

Besner, D. (1987). Phonology, lexical access in reading, and articulatory suppression: A critical review. 
Quarterly Journal of Experimental Psychology A, 39, 467-478.

Binder, J., Frost, J., Hammeke, T., Cox, R., Rao, S., \& Prieto, T. (1997). Human brain language areas identified by functional magnetic resonance imaging. Journal of Neuroscience, 17, 353-62.

Blank, S. C., Scott, S. K., Murphy, K., Warburton, E., \& Wise, R. J. (2002). Speech production: Wernicke, Broca and beyond. Brain, 125, 1829-1838.

Brown, G. D. (1987). Phonological coding in rhyme and homophony judgment. Acta Psychologia, 65, 247-262.

Buchsbaum, B., Hickok, G., \& Humphries, C. (2001). Role of left posterior superior temporal gyrus in phonological processing for speech perception and production. Cognitive Science, 25, 663-678.

Burani, C., Vallar, G., \& Bottini, G. (1991). Articulatory coding and phonological judgments on written words and pictures: The role of the phonological output buffer. European Journal of Cognitive Psychology, 3, 379-398.

Caplan, D. (1992). Language: Structure, processing, and disorders. Cambridge, MA: MIT Press.

Caplan, D., \& Waters, G. (1992). Issues arising regarding the nature and consequences of reproduction conduction aphasia. In S. E. Kohn (Ed.), Conduction aphasia. Hillsdale, NJ: Lawrence Erlbaum Associates, Inc.

Caramazza, A., Basili, A. G., Koller, J. J., \& Berndt, R. S. (1981). An investigation of repetition and language processing in a case of conduction aphasia. Brain and Language, 14, 235-271.

Caramazza, A., Miceli, G., \& Villa, G. (1986). The role of the (output) phonological buffer in reading, writing and repetition. Cognitive Neurospychology, 3, 59-85.

Content, A., Mousty, P., \& Radeau, M. (1990). Brulex: Une base de données lexicales informatisées pour le français écrit et parlé. L'Année Psychologique, 90, 551-566.

Damasio, A. R. (1992). Aphasia. New England Journal of Medicine, 323, 531-539.

Dell, G. S., Schwartz, M. F., Martin, N., Saffran, E. M., \& Gagnon, D. A. (1997). Lexical access in aphasic and nonaphasic speakers. Psychological Review, 104, 801-939.

Fadiga, L., \& Craighero, L. (2003). New insights on sensorimotor integration: From hand action to speech perception. Brain and Cognition, 53, 514-524.

Fadiga, L., Craighero, L., Buccino, G., \& Rizzolatti, G. (2002). Speech listening specifically modulates the excitability of tongue muscles: A TMS study. European Journal of Neuroscience, 15, 399-402.

Fadiga, L., Fogassi, L., Pavesi, G., \& Rizzolatti, G. (1995). Motor facilitation during action observation: A magnetic stimulation study. Journal of Neurophysiology, 73, 2608-2611.

Feinberg, T., Rothi, L., \& Heilman, K. (1986). Multimodal agnosia after unilateral left hemisphere lesion. Neurology, 36, 864-867.

Fowler, C. A., Brown, J. M., Sabadini, L., \& Weihing, J. (2003). Rapid access to speech gestures in perception: Evidence from choice and simple response time tasks. Journal of Memory and Language, 49, 396-413.

Gathercole, S. E. (1999). Cognitive approaches to the development of short-term memory. Trends in Cognitive Sciences, 3, 410-419.

Gathercole, S. E., Service, E., Hitch, G. J., Adams, A. M., \& Martin, A. J. (1999). Phonological short-term memory and vocabulary development: Further evidence on the nature of the relationship. Applied Cognitive Psychology, 13, 65-77.

Geschwing, N. (1970). The organization of language Q3 and the brain. Science, 170, 940-944.

Goodglass, H. (1992). Diagnosis of conduction aphasia. In S. E. Kohn (Ed.), Conduction aphasia. Hillsdale, NJ: Lawrence Erlbaum Associates, Inc.

Hanley, J. R., Dell, G. A., Kay, J., \& Baron, R. (2004). Evidence for the involvement of a nonlexical route in the repetition of familiar words: A comparison of single and dual route models of auditory repetition. Cognitive Neuropsychology, 21, 147-158.

Hanley, J. R., \& Kay, J. (1997). An effect of imageability on the production of phonological errors in auditory repetition. Cognitive Neuropsychology, 14, 1065-1084.

Hanley, J. R., Kay, J., \& Edwards, M. (2002). Imageability effects and phonological errors: Implications for models of auditory repetition. Cognitive Neuropsychology, 19, 193-206.

Heim, S., Opitz, B., Muller, K., \& Friederici, A. (2003). Phonological processing during language production: fMRI evidence for a shared production comprehension network. Cognitive Brain Research, 16, 285-296.

Hillis, A., \& Caramazza, A. (1991). Mechanisms for accessing lexical representations for output: Evidence from a category-specific semantic deficit. Brain and Language, 40, 106-144.

Howard, D., \& Franklin, S. (1987). Three ways for understanding written words, and their use in two contrasting cases of surface dyslexia. In 
D. A. Allport, D. MacKay, W. Prinz, \& E. Scheerer (Eds.), Language perception and production; common processes in listening, speaking, reading and writing. London: Academic Press.

Howard, D., \& Franklin, S. (1990). Memory without rehearsal. In G. Vallar \& T. Shallice (Eds.), Neuropsychological impairments of short-term memory. Cambridge, UK: Cambridge University Press.

Howard, D., \& Nickels, L. (2005). Separating input and output phonology: Semantic, phonological, and orthographic effects in short-term memory impairment. Cognitive Neuropsychology, 22, 42-77.

Iacoboni, M., Woods, R., Brass, M., Bekkering, H., Mazziotta, J., \& Rizzolatti, G. (1999). Cortical mechanisms of human imitation. Science, 24, 2526-2528.

Indefrey, P., \& Levelt, W. J. M. (2004). The spatial and temporal signatures of word production components. Cognition, 92, 101-144.

Jacquemot, C., Pallier, C., LeBihan, D., Dehaene, S., \& Dupoux, E. (2003). Phonological grammar shapes the auditory cortex: A functional magnetic resonance imaging study. Journal of Neuroscience, 23, 9541-9546.

Johnston, R. S., \& McDermott, E. A. (1986). Suppression effects in rhyme judgment tasks. Quarterly Journal of Experimental Psychology, 38, 111-124.

Kohn, S. E., \& Smith, K. L. (1990). Between-word speech errors in conduction aphasia. Cognitive Neuropsychology, 7, 133-147.

Levelt, W. J. M. (1983). Monitoring and self-repair in speech. Cognition, 14, 41-104.

Levelt, W. J. M. (1989). Speaking: From intention to articulation. Cambridge, MA: MIT Press.

Levelt, W. J. M., Roelofs, A., \& Meyer, A. (1999). A theory of lexical access in speech production. Behavioral and Brain Sciences, 22, 1-38.

Liberman, A., Cooper, F., Shankweiler, D., \& Studdert-Kennedy, M. (1967). Perception of the speech code. Psychological Review, 74, 431-461.

Liberman, L., \& Mattingly, I. (1985). The motor theory of speech perception revised. Cognition, 21, 1-36.

Martin, N., Dell, G. S., Saffran, E. M., \& Schwartz, M. F. (1994). Origins of paraphasias in deep dysphasia: Testing the consequences of a decay impairment to an interactive spreading activation model of lexical retrieval. Brain and Language, 47, 609-660.

Martin, R., Lesch, M., \& Bartha, M. (1999). Independence of input and output phonology in word processing and short-term memory. Journal of Memory and Language, 41, 3-29.
Martin, N., \& Saffran, E. M. (1992). A computational account of deep dysphasia: Evidence from a single case study. Brain and Language, 43, 240-274.

Martin, N., \& Saffran, E. M. (2002). The relationship of input and output phonology in single word processing: An evaluation of models and evidence to support them. Aphasiology, 16, 107-150.

Masoura, E. V., \& Gathercole, S. E. (2005). Contrasting contributions of phonological shortterm memory and long-term knowledge to vocabulary learning in a foreign language. Memory, 13, 422-429.

Matsumoto, R., Nair, D. R., LaPresto, E., Najm, I., Bingaman, W., Shibasaki, H., et al. (2004). Functional connectivity in the human language system: A cortico-cortical evoked potential study. Brain, 127, 2316-2330.

McCarthy, R. A., \& Warrington, E. K. (1984). A two route model of speech production: Evidence from aphasia. Brain, 107, 463-485.

McGuire, P. K., Silbersweig, D. A., \& Frith, C. D. (1996). Functional neuroanatomy of verbal selfmonitoring. Brain, 119, 907-917.

Monsell, S. (1987). On the relation between lexical input and output pathways for speech. In A. Allport et al. (Eds.), Language perception and Q4 production: Relationships between listening, speaking, reading, and writing. New York: Academic Press.

Motley, M. T., Camden, C. T., \& Baars, B. J. (1982). Covert formulation and editing of anomalies in speech production: Evidence from experimentally elicited slips of the tongue. Journal of Verbal Learning and Verbal Behaviour, 21, 578-594.

Nickels, L., Howard, D., \& Best, W. (1997). Fractionating the articulatory loop: Dissociations and associations in phonological recoding in aphasia. Brain and Language, 56, 161-182.

Nishitani, N., \& Hari, R. (2000). Temporal dynamics of cortical representation for action. Proceedings of the National Academy of Sciences of USA, 18, 913-918.

Ojemann, G. (1983). Brain organization for language from the perspective of electrical stimulation mapping. Behavioral and Brain Sciences, 6, 189-230.

Patterson, K., \& Lambon Ralph, M. A. (1999). Selective disorders of reading? Current Opinion in Neurobiology, 9, 235-239.

Peterson, R. R., \& Savoy, P. (1998). Lexical selection and phonological encoding during language production: Evidence for cascaded processing. Journal of Experimental Psychology: Learning, Memory and Cognition, 24, 539-557. 
Poeppel, D., \& Hickok, G. (2004). Towards a new functional anatomy of language. Cognition, 92, 1-12.

Price, C., Wise, R., Warburton, E., Moore, C., Howard, D., Patterson, K., et al. (1996). Hearing and saying: The functional neuroanatomy of auditory word processing. Brain, 119, 919-931.

Rizzolatti, G., Fadiga, L., Gallese, V., \& Fogassi, L. (1996a). Premotor cortex and the recognition of motor actions. Cognitive Brain Research, 3, 131-141.

Rizzolatti, G., Fadiga, L., Matelli, M., Bettinardi, V., Paulesu, E., Perani, D., et al. (1996b). Localization of grasp representations in humans by PET: Observation versus execution. Experimental Brain Research, 111, 246-252.

Saito, A., Yoshimura, T., Itakura, T., \& Lambon Ralph, M. A. (2003). Demonstrating a wordlikeness effect on nonword repetition performance in a conduction aphasic patient. Brain and Language, 85, 222-230.

Schriefers, H., Meyer, A., \& Levelt, W. J. M. (1990). Exploring the time course of lexical access in language production: Picture-word interference studies. Journal of Memory and Language, 29, 86-102.

Schwartz, M. F., Dell, G. S., Martin, N., \& Saffran, E. M. (1994). Normal and aphasic naming in an interactive spreading activation model. Brain and Language, 47, 391-394.

Q1 Seidenberg \& McClelland, 1989

Shallice, T., \& Butterworth, B. (1977). Short-term memory impairment and spontaneous speech. Neuropsychologia, 15, 729-735.

Shallice, T., McLeod, P., \& Lewis, K. (1985). Isolating cognitive modules with the dual-task paradigm: Are speech perception and production separate processes? Quarterly Journal of Experimental Psychology A, 37, 507-532.

Shallice, T., Rumiati, R., \& Zadini, A. (2000). The selective impairment of the phonological output buffer. Cognitive Neuropsychology, 17, 517-546.

Strafella, A., \& Paus, T. (2000). Modulation of cortical excitability during action observation: A transcranial magnetic stimulation study. Neuroreport, 14, 2289-2292.

Vallar, G., \& Baddeley, A. D. (1984). Fractionation of working memory: Neuropsychological evidence for a phonological short-term store. Journal of Verbal Learning and Verbal Behaviour, 23, 151-161.

Vigliocco, G., Antonini, T., \& Garret, F. (1999). Grammatical gender is on the tip of Italian tongues. Psychological Science, 8, 314-317.

Waters, G. S., Rochon, E., \& Caplan, D. (1992). The role of high-level speech planning in rehearsal: Evidence from patients with apraxia of speech. Journal of Memory and Language, 31, 54-73.

Wheeldon, L., \& Levelt, W. (1995). Monitoring the time course of phonological encoding. Journal of Memory and Language, 34, 311-334.

Wilshire, C. E., \& McCarthy, R. A. (1996). Experimental investigations of an impairment in phonological encoding. Cognitive Neuropsychology, 13, 1059-1098.

Wise, R. J., Scott, S. K., Blank, S., Mummery, C. J., Murphy, K., \& Warburton, E. A. (2001). Separate neural subsystems within "Wernicke's area". Brain, 124, 83-95. 


\section{APPENDIX}

Performance of patient F.A. on a French version of the Boston Diagnostic Aphasia Examination

\begin{tabular}{|c|c|c|c|}
\hline & Subtests & Scores & Normal range limits \\
\hline \multirow[t]{4}{*}{ Auditory comprehension } & Word discrimination & $72 / 72$ & $N>55$ \\
\hline & Body-part identification & $19 / 20$ & $N>15$ \\
\hline & Command & $14 / 15$ & $N>10$ \\
\hline & Logical reasoning & $11 / 12$ & $N>5$ \\
\hline \multirow[t]{2}{*}{ Fluency } & Articulation rating & $7 / 7$ & $N>5$ \\
\hline & Phrase length & $7 / 7$ & $N>5$ \\
\hline \multirow[t]{2}{*}{ Automatic speech } & Automatized sequences & $9 / 9$ & $N>5$ \\
\hline & Reciting & $1 / 2$ & $N>1$ \\
\hline \multirow[t]{3}{*}{ Repetition } & Repetition of words & $10 / 10$ & $N>7$ \\
\hline & Concrete sentences & $6 / 8$ & $N>5$ \\
\hline & Abstract sentences & $2 / 8$ & $N>2$ \\
\hline \multirow[t]{2}{*}{ Reading aloud } & Words & $30 / 30$ & $N>19$ \\
\hline & Sentences & $10 / 10$ & $N>5$ \\
\hline \multirow[t]{4}{*}{ Naming } & Responsive naming & $30 / 30$ & $N>22$ \\
\hline & Confrontation naming & $105 / 105$ & $N>70$ \\
\hline & Animal naming & $17 / 23$ & $N>7$ \\
\hline & Body-part naming & $27 / 30$ & $N>19$ \\
\hline \multirow[t]{2}{*}{ Paraphasia } & Phonological \& morphological & $3 / 16$ & $N<5$ \\
\hline & Semantic & $6 / 24$ & $N<7$ \\
\hline \multirow[t]{4}{*}{ Written comprehension } & Auditory-written word matching & $8 / 8$ & $N>7$ \\
\hline & Spelled words & $8 / 8$ & $N>3$ \\
\hline & Picture-written-word matching & $10 / 10$ & $N>7$ \\
\hline & Text reading & $4 / 10$ & $N>5$ \\
\hline \multirow[t]{4}{*}{ Writing } & Dictation & $13 / 15$ & $N>10$ \\
\hline & Written denomination & $10 / 10$ & $N>5$ \\
\hline & Graphical evocation & $9 / 10$ & $N>4$ \\
\hline & Description & $3 / 4$ & $N>2$ \\
\hline
\end{tabular}




\section{LIST OF ITEMS USED IN THE REPETITION TASK}

Words

accalmie; acrobate; allusion; araignée; autobus; bâton; bévue; bidet; bison; boeuf; buse; cabanon; caisse; canard; canari; capitaine; chacal; chaloupe; chat; cheminot; cheval; chevalier; chien; choix; cochon; combine; confidence; coq; cotillon; couette; crabe; départ; devinette; dignité; dîme; dindon; dinosaure; divan; écolier; éléphant; épervier; escalier; éventail; faon; forgeron; fraude; gâchis; guêpe; inertie; jupe; lapin; limbes; lime; lion; lionne; louve; macaque; magie; manie; manne; méthode; morue; mouche; mouton; mulot; musicien; mygale; opticien; pantalon; papillon; parchemin; paysan; pendule; phase; philosophe; phoque; pigeon; pince; pipeau; pouf; puits; puma; rabot; règne; renouveau; séquelle; serpent; singe; taupe; taureau; titulaire; ustensile; vache; vœu; voûte; wagon.

\section{Pseudowords}

acouloir; alitude; apiler; balaj; banar; banoume; bira; bojéral; bouguet; bube; charet; cripe; croupillon; dasse; dinru; drai; durista; gline; gonvi; gouchet; graiche; grotinfi; guipe; jal; katal; kavet; krituro; motilar; moupin; nuon; padisté; palisteux; paton; pezou; phopographe; picaque; pioube; psu; serpitude; sinpofi; sopar; sukurer; tassioné; teugue; teuve; zanze; zonfe; zoua.

\section{LIST OF THE WRITTEN WORDS USED IN THE RHYME JUDGEMENT TASK}

\author{
Auditory rhyme orthographically similar \\ mémoire / armoire \\ sillon / réveillon \\ antilope / magnétoscope \\ acide / aride \\ château / couteau \\ cheval / rival
}

sort / tort

bague / vague

ligne / consigne

vélo / pédalo

Auditory nonrhyme orthographically dissimilar

orange / biscuit

lampe / stylo

radiateur / barrage

escalier / râteau

abricot / main

épouvantail / locomotive

feuille / port

gare / melon

lunette / peinture

chaussure / griffe

Auditory rhyme orthographically dissimilar

femme / gramme

faon / éléphant

acrobatie /aussi

rhinocéros / féroce

six / caprice

sept / chaussette

cactus / puce

coq / époque

garçon / poisson

balbutier / bénéficier

Auditory nonrhyme orthographically dissimilar

plus / dessus

jadis / radis

taffetas / vasistas

barman / artisan

abdomen / examen

adéquat / avocat

tranquille / fille

bénitier / initier

égyptien / entretien

ambiguë / digue 


\section{PCGN168304}

Queries

Anne-Catherine Bachoud-Lévi

Q1 Seidenberg \& McClelland, 1989. Not in refs.

Q2 $p<10^{-3}$ changed to $p<.001$ throughout, OK?

Q3 Geschwing (1970) in refs. Geschwind in text.

Q4 Monsell (1987). Give names of all editors, unless very large number (APA 5: 4.13, p. 229). 